\section{Briginal intricles.}

\section{THE THCHNIC TO BE OBSERVED IN THE EXAMINATION ANI) LOCAL TREATMEN'T OF" 'THE UPPER RECIUN ANI) PISLIC COJ,ON.}

BY T. CnITTENIEN Hit, M.n.,

Surpeon to the Rectal Department of the Boston Dispensary, Boston.

$\Lambda \mathrm{r}$ the present time there exists in the profession al general manifestation of interest and realization of the important bearing that certain local lesions and structural changes, brought alout by catarhal and inflammatory conditions of the rectum and sigmoid, may have as etiologieal factors in the causation of chronic constipation, ahronic diarrhca, so-called mucous eolitis, ulcerative colitis, reflex symptoms of both the male and female renito-urinary organs, as well as various aches and pains of the rectal, sacral and lumbar regions.

The reason for this aroused interest in old subjects may be attiributed to the rather recent cliscovery that the upper rectum and pelvic colon can be thoroughly explored and many localized inflammatory processes treated, and even operative procedures carried out through the electrirally lighted sigmoirloseope.

$\Lambda$ number of original workers, both in this eountry and abroad, have during the past four or five years thrown much light on some of these oleseure disorders, at the same time sugresting more rational methods of treatment.

While recognizing the fact that it may properly bo said that the whole subjest, is in a sense in an evolutionary stage of development, yet the first principles and primary general truths have been studied, their importance recognized and established beyond a question of doubt.

'Thus our knowledge of these conditions which have necessarily been founded chiefly on the symptoms which they produce, and a physical examination, such as abdominal palpation or at most the examination of the feces are, at the present time, supplemented and simplified by direct instrumental examination of the bowel.

The result has been that our views have been considerably altered as to the pathology of the cliseases just mentioned, and altogether different, methods of treatinent have sugrested themselves.

The sigmoidoscope has been to the writer a very necessary adjunct in his efforts to accurately diagnose and treat some of the more diffieult of these cases. Inasmuch as even recent graduates of our best medieal sehools receive but little instruction in this important domain of surgery, a description of the technic employed and certain practical suggestions may be of interest to some who have not had the opportunity for studying the diseases of the lower portion of the howel. The qualified graduate of to-day has prepared for the practice of medicine by attending special clinies where he has becn afforcled an opportunity to gain a general knowledge of nearly every department of medicine and surgery, with the notable exception of diseases common to the rectum and sigmoid.
Such being the case it is scarcely to be wondered at that many otherwise skillful practitioners imagine great difficulties to surround the correct diagnosis of these cases, and more often than otherwise the treatiment undertaken is entirely of a perfunctory and haphazard nature.

'The remarks that follow are not intended to convey the impression that every patient applying for treatment for constipation, diarrhea or mucous colitis should at once be put to the inconvenience of a sigmoidoscopic examination.

Nevertheless, I am convinced that a systematic examination of some of the more obstinate of these cases, not lenefited by intelligent medical treatinent, would disclose definite lesions, or at least inflammatory conditions of the mucous membrane of the rectum or sigmoid which must be corrected before any other treatment will be of much avail.

PREPARATION OF THE PATLEN' FOR IXXAMINATION.

Inasmuch as rectal examinations are distasteful to many, and for the further reason that many patients are imbued with the impression that instrumental examinations of this region of the body are particularly painful, I shall give much attention to details, the description of which it is hoped will not prove tiresome.

With the patient, properly prepared there is nothing abouti a rectal examination that is any more disagrecable than an exploration of any of the cavities of the body, and when dexterously conducted it should not cause any more discomfort. Save in exceptional instances any table, such as is procurable in the ordinary houschold, will serve for a satisfactory examination. 'The elbows and knees for male patients, and the right lateral semi-prone for women are the casiest positions in which to conduct the preliminary examination.

In the first position the whole peri-anal region is readily accessible without the aid of an assistant, while in the latter the patient, if an assistant is not at hand, can facilitate the examination by supporting the left buttock.

The swent and sebaceous glands in the immediate vicinity of the anus are numerous and large, and for this reason the anal orifice should be cleansed by thoroughly wiping with absorbent cotton, which has been wrung dry of some antiseptic solution. After carefully inspecting and palpating all about the anus, the index finger with soap under the nail (if gloves are not used) is smeared with a stiff lubricant, and gently inserted with a rotary motion into the rectum. It is unnecessary to soil the finger with fecal material as its presence should be noted before actual contact takes place. When the rectum is found to contain feces, a small enema of boric acid solution, "not cxcceding ten ounces, will quickly empty the rectum and likewise the sigmoid in many instances, in such a manner as to permit of instrumental examination. The sirall enema will almost invariably answer for exploration of the rectum itself, but in atonic conditions of the large intestine it will be found necessary 
to ask the patient to call later and be prepared as follows: on the morning preveding the day sel. for cexamination, 3 to 6 dr. of magnesium sulphate or a sulitalsle close of some saline mineral Water shombl be taken.

'Pluce homs hefore coming to the office, the bowel is further cleansed with a larege enema of normal saline solution taken in the knee-chest. posture, followed two hours later by the injection of half a pint of rlear water containing an ounce of glycerin. 'This last enema should never exreed the amount stipulated, for if larger some may remain in the sigmoid and cause moch annoyance by heing discharged during the examination or treatment.

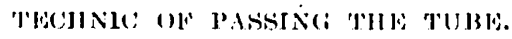

It is difficult to formulate definite rules as to the lechuic of exploring the sigmoid. It is easier and much more satisfacetory to demomstrate to the loginner the principles involved than to leserilse it, and then with a little practice any one who has had previous experience in the use of similar instruments, can accustom one's self to passing the tube in a manner that will be entirely silfe and satisfactory to both patient and surgeon.

It is reaclily apparent to all, that the greatest 'are and caution should be exercised in passing the sigmoidoscope, especially when there is an icelive ulcerative condition of the bowel, or other inflimmatory condition of the neighboring organs. A rase' has recently been reported by (a. Sultan in which perforation of the rectum near the rectosiemoiclal juncture took place during a sigmoidoscople examination. 'The patient, a woman aged fifty-three, was suffering from chronic eatarrh of the large intestine. The instrument was reaclily passed for $20 \mathrm{~cm}$. At this point distention with air was hegun. During the distention the paltient complained suddenly of great distress, and at the same noment sultan rould sce in the sigmoidoscope the serous membrane right before lim lulging into the rectum. He describes in much detail the repair of the injury. Immediate lapanotomy ---suturing the rent and the finding of a particle of fecal matter the size of a cherry in the lower true pelvis. The patient died seven weelis later, and in the depth of the abdomen was found an encapsulated alscess.

Nolwithstanding this unfortunate experience he concludes his paper with the statement " that: in the rectoscope we have a distinct aid which is not possible in any other manner or method in forming a decision concerning changes in the rectum or sigmoid. We must, however, always hear in mind how dangerous this instrument can be of which we make use."

There are reported instances in which rough landling and undue force in passing the tube has been followed by perforation of the bowel, and the instrument has passed on into the peritoneal ravity.

Such mothods, however, are absolutely unjustifiable, and if the rule is followed to vise no foree after the end of the sigmoidoseope has passed

1 Jeut. Zeitschr. für Chir., p. 307. the anal sphincters no such serious eomplications (an possibly arisc.

Before introducing the tube the patient should le made as amfortable as possible in the grentpecitoral position.

If for some reason this posture is impossible? because of an anchylosed or amputated lower extremity or great discomfort of assuming this position, the lateral semi-prone with the knees well drawn "1) on the abdomen thay he substituted.

In fact. this latier position is favored by some proctologists for asthetic reasons, elaiming that, it is much pleasinter for women and hypersensitive indivicluals, but the writer believes that the greater case with which the instrument is passed and so much less discomfort is oreasioned the patient that, the genu-pectomal position should nearly always be the one of preference.

The passage of any instrument into the reet.um is rendered less difficult by first inserting the finger past the sphincters. 'This procedure dilates and lubricates the anal ('anal, as well as affords the surgeon opportunity to ascertain the cxact direction in which the instrument should be guided before the obturator is withdrawn.

The sigmoidoseope, warm and smeared with vaseline, should be pressed firmly over the anal orifice, the patient at the samie time heing requested to strain down, thus relaxing the sphincters. Steady firm pressure, in a downward and forward direction, should be made on the handle of the instrument until it has passed the anal camal. After this portion has heen passed, the handle should first be gradually lowered and pushed forward until the end of the instrument. has reached the middle portion of the sacrum. At this point the obturator should be withdrawn, which will allow the bowel to hecome distended with air so that the tube (an he pasised onwald by sight. 'The instrument, is then crimlually raised, allowing it to be gently pushed onward to the promontory of the sacium, where ronsiderable resistance to the onward prowess of the instrument is met with. A great cleal of clifficulty is experienced by the beginner in passing the instrument into the sigmoid, becanse of a well developed fold of mucous membrane, known at O']eirne's sphincter, situated at the junction of the sigmoid and rectimm. 'This valve--like splineter frequently makes the rectumi appear to end abruptly in al blind pocket. If careful seareh now be made, the valve will be located in elose? apposition to the opposite wall of the gut. It can then be effaced with the end of the instirument so as not to retard its further progress into the sigmoid flexure. From now on the directions usually given are to make slight pressure on the hand bull of the pneumatic signoidoseope which will sufficiently inflate the gut so that it may be inserted to its full extent, and the whole interior of this portion of the intestine brought plainly into view. During the past year I have practically discarded the hamd bulli as l have found that by placing the patient in a good proetescopic position it is rarely required. Its use is 
often very distressing and in uleerative eonclitions it must be regarded as a dangerous practice. In

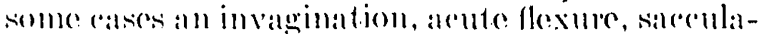
tion. or matrowing of the caliber of the gut will not of le straightened ont hy air insullation. Air will bass theoum such places ansing eomsiderahle distention without one's being anare of it, molest the patient romplans of aldominal pain. lt is in

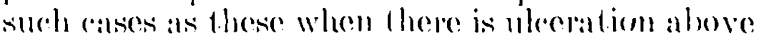
that the gereatest dangere lies.

If the onwater progess of the instemment is imperled it is hettex to shlightly withdraw the instrument. get the digeretion of the gut and reinsert the ohturator which will allow the tulee 10 he passed with less incomsoniches to the patient. 'This manemoer and les repeated motil fle tuhe has heen passed as falr als desireal.

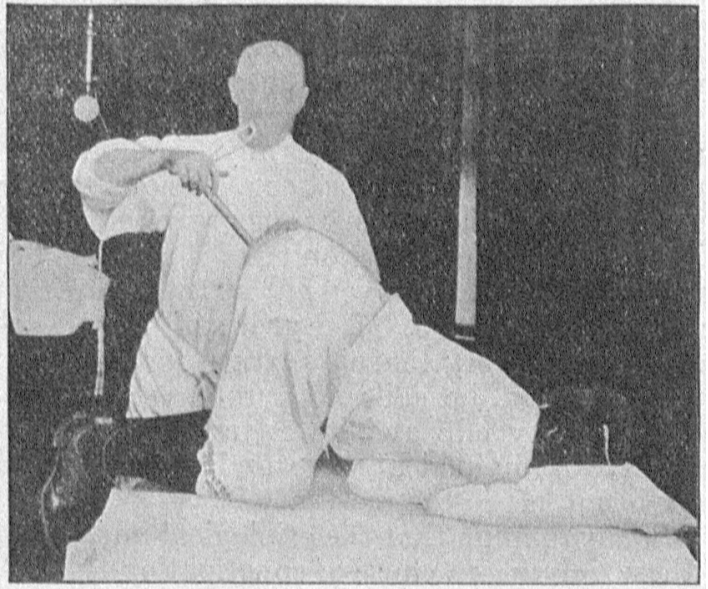

lin. 1. Redative dired ion of the talse when pussing the sphineters

the photographls here reproduced are intended 10 give in a general way the relative direction of the tube: when passing the sphineters (lig. 1).

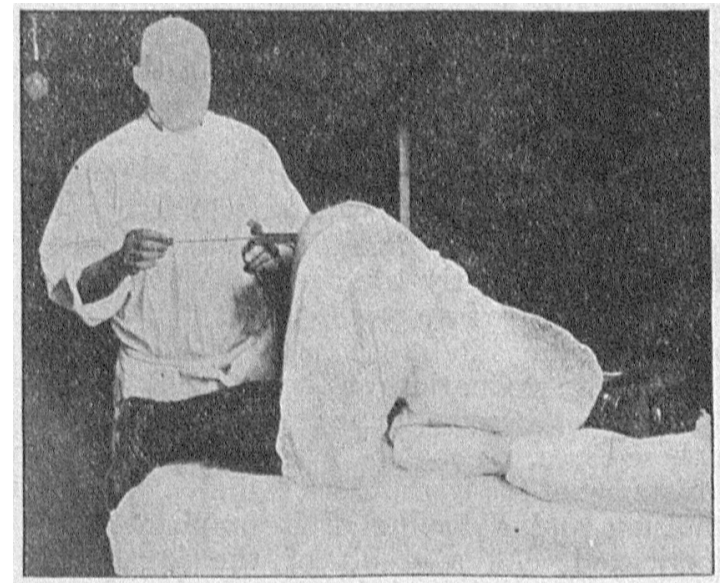

Fui,: The end of the tule has remelhed the midelle portion of the satelum. The obturater should be withdrawn at this point.

when it has reached the midalle portion of the salcrum (lig. 2), its passage over the promontory offtho sacem (lig. 3), and when inside the polvic rolon (Fig. 4). The great majority of sigmoidoscopic examinations are conducted without the use of general anesthesia. Oe(asionally, howerer. it is desirable when there are painful affections about the anus, of the patient is apprehensive? of heing hurt. lt should alwatys be horme in mind when employing ether that there is murh more danger of injury to the intestine as we do nothave the patient's sensations to wath us when making 100 much presisure or distention.

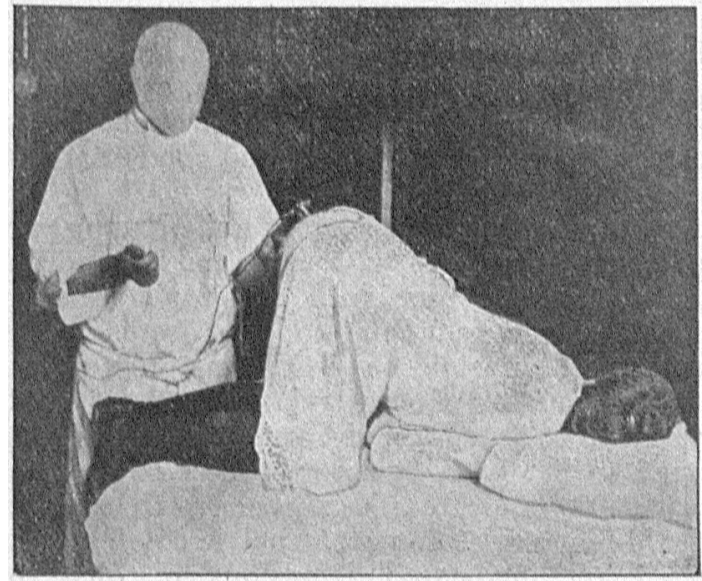

Fici, 3. Passing the tube over the promontory of the saterum,

We have, therefore, in the simmoidescope: an instrument of presision which should he resorted to in the treatment of many eomelitions which are dependent on eatarthal infammatioms of the rectum or pelvic colom, such as hyperteophice ame aterophic: ratareh, trammatice, tubereular and

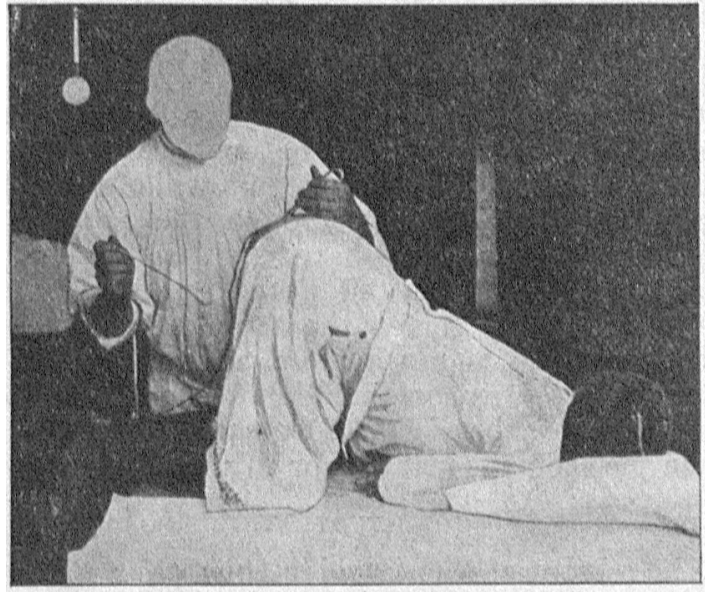

Futi, t. The tube insinle the pelvic colden.

spereife uleeration, otr. IVith the lesions hrought. plainly into view and easy of reach, direct fopical applications to the diseased tissures may he made which will prove more effective than the more commonly employed medicated enemas amb suppositories.

('HRONL: DIARKHLA.

('ases of ehromice diarrhea that have resisted careful medical treatment are often ansed ly circumscribed nlcerated areats of the reotum of 
sigmoid which are readily accessible through the sigmoidoscope.

Through the courtesy of different members of the Medical Staff of the l3oston Dispensary, I have had an opportunity of examining and treating many such cases, and frequently lesions have been discovered that yielded very promptly to local treatment.

The plan of treatment carried out was briefly as follows: The restriction of the diet to nonirritating foods such as milk, soft boiled eggs, gruels, boiled rice, nourishing soups, etc., as well as the avoidance of cold, acid or alcoholic beverages, greasy and highly seasoned foods and excesses of tea or coffee.

The local treatment mainly relied upon was high colonic flushings with horic acid or normal salt solution, together with the topical use of nitrate of silver, from one to two drams to the ounce, to all abrasions or ulcerations present. In some cases instead of the silver solution, icthyol in glycerin $15 \%$, or balsam of P'eru in castor oil $15 \%$, secmed to act with better results. Those cases in which there are reasons to believe that pathological lesions exist above the pelvic colon may be treated by medicated emulsions of olive oil through a long colon tube.

The thorough flushing of the colon is very soothing and healing to an inflamed and ulcerated mucosa, and when supplemented with the above and topical applications, much can be done to check the copious and frequent diarrheal discharges. A diarrhea dependent upon a localized or general enteritis of course would not be benefited by local treatment, but many of these cases are well of the disease of the small intestine, yet there remains the ulcerated or inflamed condition of the colon or rectum.

Cases of ulcerative colo-proctitis, especially if of a syphilitic or dysenteric nature, which prove obstinate to treatment per rectum will of ten yield readily to colon flushing through the appendix. The operation was originated by $\mathrm{Dr}$. Robert $\mathrm{F}$. Weir, of New York, and if the appendix is of sufficient caliber serves the same purpose as a cecostomy and is much more agreeable to the patient for the reason that the former operation does not allow the escape of feces as often happens when the cecum is utilized for this purpose.

\section{CONSTIPATION.}

The advent of the sigmoidoscope gave a fresh impetus to the study of constipation, as it was very interesting to note in what particulars the rectum and sigmoid? of 'a' patient who habitually carricl about a load of fecal material in these organs, varied from the normal. The subject of constipation is a large one involving the chemistry of digestion, dieteties, etc., as well as mechanical obstructions and inflammatory conditions of the abdominal organs. Leaving all these general and complex questions, I will mention briefly the treatment of certain conditions that are frequently met with in the terminal portion of the digestive tract.

In all cases, the usual routine of regular time of going to stool, the correction of errors of diet, eating plenty of fruit and drinking an abundance of water, out-of-door cxercise, gymnasties, etc., when possible should be insisted upon. Abdominal massage and lineading of the colon is often a valuable adjunct to other treatment.

The valves of Houston congenitally enlarged or hypertrophied and stiffenerl, as a result of catarrhal inflammation, may be the rause of constipation. 1)r. T. (. Martin, of Washington, was the first to recognize this fact and recommend the operation of valvotomy for its relief.

])r. Martin's operation consisted in incising through the proctoscope the valve or valves and suturing the free border, which operation he still advocates. The procedure, however, exeept in skilled hands, may be attended with hemorrhage or fatal puncture of the bowel. Various automatic valve clips have heen made which serve the same purpose by dividing the valves by pressure necrosis, and when these are used there is no danger of hemorrhage or perforation. Should the peritoneum by any possibility be included in the valve it causes adhesions to form between the two layers and thus prevents perforation and subsequent peritonitis. The clips come away with the fecal movement at the end of four or five days. Jr. J. M. Iynch, of New York, has devised a very ingenious instrument for this purpose, which he calls a thyrotome. It is an electro-cautery clip and its advantages are thit the valve is divided at once and thus a foreign body is not left in the rectum.

It is my opinion that the etiological importance of these valves as a cause of constipation has been somewhat overestimated, but occasional cises will be met with where the valves form an ohstruetion which ean be dealt with in no other wiy. I believe it is always better to try a palliative course of treatment before division. Emptying of the rectum of any retained feces by an 8-0\%. enema of boric acid solution after the bowels have moved in the morning will improve the catarrhal condition which is always present in these overloaded recti. Two or three times a week the valves should be massaged for five minutess through the proctoscope with an applicator protected by absorbent cotton which has been dipped in olive oil. Persistence in this massage will very frequently change a stiffened and obstructing valve into one so pliant that it cannot. possibly be any hindrance to the fecal current.

Chronic invagination of the sigmoid or upper rectum is not an uncommon cause of constipation. In these cases, no matter what the character or consistency of the feces, there is difficulty in their expulsion and a feeling of incomplete relief is experienced. As a result of the invagination superficial ulceration of the sigmoidal and rectial mucosa is soon produced, and this may he manifested by the discharge of mueus sometimes streaked with blood and pus. By careful digital examination one may feel the invaginating sigmoid, and through the proctoscope it may be seen as the patient strains down.

The treatment may be either palliative or opera- 
tive. 'The palliative will sometimes prove successful,and consists in replacement by air dilatation with the pneumatic proctoscope with the patient in thejknce-chest position. After such replacement of the gut the bowels will sometimes act regularly for a few days, and persistence in this line of treatment may effect a cure. At the sane time ulcerations present are treated by direct topical applications. Should palliative measures prove of no avail the suturing of the sigmoid to the abdominal wall (sigmoidopexy) will prevent the invagination.

Stricture of the rectum should not be forgotten in this comnection. I have seen several cases that had received prolonged medicinal treatment without the real cause being ascertained. In two cases the stricture was annular and situated just within the internal sphincter and barely admitted the cxamining finger.

Hypertrophy and spasm of the external sphincter muscle is a more common cause of constipation than is generally supposed. In these cases usually a small ulcer will be found somewhere in the anal canal, which is irritated by the fecal discharges and thus keeps up the spasm and rigidity of the muscle. The treatment for this condition is the same as that for anal fissure.

\section{RIECIAL CANCER.}

Notwithstanding the accuracy with which rectal cancer can now be diagnosed, it is a fact, most surgeons will agree to, that an carly diagnosis is made out in only a small percentage of the patients that present themselves for operation. l'erhaps not more than one fifth of the cases are suitable for radical operation, yet these growths of the lower rectum can be easily recognized by digital examination alone, while those of the IIpper rectum and pelvic colon can nearly always he accurately located with the sigmoidoscope. should there be doubt as to the nature of the neoplasm it can be differentiated from other tumors by removing a portion for microscopical examination.

In the early stages when the growth is small bi-manual palpation is unreliable. Exploratory incision is probably the surest method of making the diagnosis, but it is only infrequently that such an operation is necessary. Cancer of the large intestine will continue to be overlooked until we, as a profession, recognize how frequently it occurs (according to late statistics three quarters of the malignant growths of the intestinal tract are located in the rectum or sigmoid) and become more discerning as to the initial symptoms of this insidious disease. It can readily be perceived that the general practitioner will frequently overlook the first vague symptoms of malignant disease of the rectum.

It is a common experience to hear these patients remark that for six months or a year previously they had consulted their physician for certain unusual sensations in the rectum, such as a feeling of weight and fullness that was only relieved by defecation; or a patient who has heretofore been regular in his habits may have complained of a gradually increasing constipation, which is a very suggestive, early symptom of malignant discase of the rectum. liven after the cardinal symptoms, such as muco-purulent or bloody stools, constipation alternating with diarrhea, etc., appear, the diagnosis may have been obscured by complications such as piles, fistula or ulceration, for such patients often appear vigorous and robust for a long, time, since the neoplasm is situated at the lower end of the digestive tract and thus has not interfered in any way with the digestion and assimilation of nourishment.

Many patients have been seen by the writer, illustrating how far advanced these cases of ten get, before they are discovered, and not until we, as physicians, make it a routine practice to examine every patient with however indefinite rectal symptoms, by means of the newer and more modern instruments at our disposal, will the mortality of rectal cancer be materially reduced.

\section{SOME FURTHER STUDIES ON NOCYURNAL PARALYSIS. \\ BY IBADOR H. CORIAT, M.D., \\ Second Assistant Physician for Diseases of the Nervous System Boston City Hospital. \\ (From the Neurological Clinic of the Boston Cüy Hospital.)}

IN a recent contribution upon this subject, ${ }^{1} \mathrm{I}$ reported the case of a woman, in whom, following a distressing emotional shock, there developed a peculiar symptom-complex. In the half-waking and half-slecping condition (hypnagogic state), there arose a state of general palsy, which, in its clinical picture, was an exact motor repetition of the original emotional episode. 'The disorder was interpreted as a functional dissociation and closely related to the temporary, general palsy that is sometimes observed in patients who are suddenly awakened from a decp hypnosis. Complete recovery took place by psychotherapeutic methods. Since reporting this case, four others of a similar nature have been observed. These have not only helped to clear the clinical aspects of the question, but have thrown considerable light on the origin and evolution of the attacks. Furthermore, a search through the literature has brought several similar contributions to light, which may be added to the papers by Weir Mitchell and Ch. Féré, already quoted.

Bleuler, ${ }^{2}$ in a subjective analysis of his sensations while hypnotized, experienced a partial palsy on awakening from the state of autohypnosis. In a discussion of the variants of dream consciousness, Jastrow ${ }^{3}$ seems to have had this condition of general nocturnal palsy in mind. He writes: "It may be pertinent to note that there seems occasionally a condition of dream stupor that may be inclueed in predisposed sleepers by sudden awakening, though it also occurs spontaneously. The subject thereof finds

'Isador H. Coriat: Nocturnal Parnlysis, Bost. Mkw. And Suna. Joun., vol. olvii, no. 2, July 11, 1007 .

Woch. Bleulor: The Pychology of Hypnotism, Minch. Med. therapy.) 